\title{
KESANTUNAN BERBAHASA DALAM NASKAH DRAMA RETNO MANGGALI KARYA HANINDAWAN DAN RELEVANSINYA SEBAGAI BAHAN AJAR BAHASA INDONESIA DI SMA
}

\author{
Siti Istiqomah, Atiqa Sabardila \\ Universitas Muhammadiyah Surakarta \\ Email: sitiistiqomah016@gmail.com,mbakatiq@gmail.com
}

\begin{abstract}
Abstrak: Salah satu jenis tindak tutur yang memungkinkan termuat dalam naskah drama adalah kesantunan berbahasa. Penelitian ini bertujuan mengidentifikasi tindak kesantunan berbahasa dalam naskah drama Retno Manggali dan relevansinya sebagai bahan ajar Bahasa Indonesia di SMA. Jenis penelitian ini adalah penelitian kualitatif dengan menggunakan pendekatan pragmatik. Teknik pengumpulan data menggunakan cara pengamatan simak dan catat karena datanya berupa teks. Validitas dalam penelitian ini menggunakan triangulasi sumber. Penelitian ini menemukan 20 data kesantunan berbahasa yang meliputi maksim kebijaksanaan 6 data, maksim pujian 2 data, maksim kedermawanan 2 data, maksim kesederhanaan 3 data, maksim kecocokan 4 data, dan maksim kesimpatian 3 data. Hasil penelitian ini relevan sebagai bahan ajar Bahasa Indonesia untuk tingkat SMA (Sekolah Menengah Atas) kelas XI pada KD 3.19 yaitu menganalisis isi dan kebahasaan drama yang dibaca atau ditonton dan dapat dikontribusikan dengan unsur intrinsik bagian amanat.
\end{abstract}

Kata Kunci: kesantunan berbahasa, naskah drama Retno Manggali, pragmatik, maksim

\section{LANGUAGE POLITENESS IN THE DRAMA TEXT OF "RETNO MANGGALI” BY HANINDAWAN AND ITS RELEVANCE AS INDONESIAN TEACHING MATERIALS IN SENIOR HIGH SCHOOLS}

\begin{abstract}
One type of speech act that may be included in a drama script is language politeness. This study aims to identify acts of politeness in the "Retno Manggali" drama script and their relevance as Indonesian language teaching materials in senior high school. This type of research is qualitative research using a pragmatic approach. The technique of collecting data uses observations and notes because the data is in the form of text. The validity of this study used source triangulation. This research found 20 data of language politeness which includes 6 data maxims of wisdom, 2 data of praise maxims, 2 data of generosity maxims, 3 data of simplicity maxims, 4 data of conformity maxims, and 3 data of conclusions maxims. The results of this study are relevant as Indonesian language teaching materials for the XI grade in senior high school level at KD 3.19, namely analyzing the content and language of the drama that is read or watched and can be contributed to the intrinsic elements of the mandate section.
\end{abstract}

Keywords: language politeness, Retno Manggali drama manuscripts; pragmatics, maxim.

BASASTRA Jurnal Bahasa, Sastra, dan Pengajarannya

Volume 9 Nomor 1, April 2021, ISSN 2302-6405 


\section{PENDAHULUAN}

Menjalin hubungan baik dengan sesama manusia membutuhkan kunci utama alat komunikasi yaitu bahasa. Bahasa memiliki peran penting dalam kehidupan kita sehari-hari, karena bahasa merupakan sarana atau alat untuk mengekspresikan diri dalam suatu lingkungan. Seseorang dikatakan berhasil dalam berkomunikasi ketika maksud tuturan yang disampaikan penutur dapat diterima dan dipahami dengan baik oleh penerima tuturan (mitra tutur) atau lawan bicara. Oleh karena itu, perihal komunikasi diperlukan aturan-aturan dalam berbahasa sehingga penutur dan mitra tutur dapat terjalin interaksi dengan baik dan sopan agar tujuan komunikasi dapat dilakukan dengan maksimal.

Prinsip kesantunan meliputi beberapa maksim. Maksim itu sendiri merupakan kaidah kebahasaan di dalam interaksi lingual; kaidah-kaidah yang mengatur tindakannya, penggunaan bahasanya, dan interpretasi-interpretasinya terhadap tindakan dan ucapan lawan tuturnya. Selain itu, maksim juga disebut sebagai bentuk pragmatik berdasarkan prinsip kerja sama dan prinsip kesopanan. Ilmu linguistik khususnya pembahasan mengenai pragmatik, kesopanan berbahasa dirumuskan oleh beberapa tokoh ahli.

Penelitian ini berfokus pada maksim kesopanan yang dikemukakan oleh Leech (1983) yang berpandangan bahwa maksim kesopanan memiliki enam maksim yaitu (1) maksim kebijaksanaan, (2) maksim penerimaan, (3) maksim kemurahan, (4) maksim kerendahan hati, (5) maksim kecocokan, dan (6) maksim kesimpatian. Aturan-aturan dalam berkomunikasi atau prinsip percakapan khususnya pada tindak kesantunan diperlukan proses tuturan untuk menjaga berlangsungnya interaksi agar terjalin komunikasi yang baik sesuai maksud yang diharapkan penutur maupun mitra tutur. Penutur dan mitra tutur akan merasa dihargai jika mendapatkan respon baik dan pastinya tidak ada unsur yang membuat sakit hati jika komunikasi terjalin dengan baik dan santun, maka dari itu analisis tindak tutur kesantunan sangat diperlukan guna mengetahui prinsipprinsip kesantunan. Pada naskah drama Retno Manggali terdapat beberapa maksim di antaranya yaitu maksim kedermawanan, seperti dialog di bawah ini

Marwi: "Ya den, sampeyan pulang saja, den ayu sepuh biar di sini saya temani. Nanti kalo kepengen-kepengen bakmi apa kopi, biar nyuruh saya." (halaman 14)

Tuturan tersebut dikatakan santun atau sopan karena masuk kategori maksim kedermawanan (kemurahan hati). Dikatakan maksim kemurahan hati yaitu memaksimalkan kerugian bagi diri sendiri dan meminimalkan keuntungan bagi diri sendiri, ditunjukkan pada penggalan di atas bahwasannya Marwi bermurah 
hati menawarkan dirinya untuk menemani ibunya Manggali.

Menurut Waluyo (2003: 158159) drama merupakan pengajaran sebagai penunjang pemahaman bahasa yang berarti untuk melatih keterampilan membaca (teks drama) dan menyimak atau mendengarkan (dialog pertunjukan drama). Sementara sebagai penunjang latihan penggunaan bahasa artinya melatih keterampilan menulis (teks drama sederhana, resensi drama, resensi pementasan) dan wicara (melakukan pementasan drama). Naskah drama mampu membantu siswa dalam meningkatkan budaya menumbuhkan karsa, cipta dan siswa mampu lebih terampil dalam berbahasa. Dari penggalan-penggalan dialog yang ada pada naskah drama siswa mampu meningkatkan budaya berbicara, membaca, dan menyimak. Selain itu, siswa dapat membedakan beberapa tuturan santun maupun tidaknya yang ada pada naskah. Paparan di atas peneliti menyimpulkan perlunya analisis tindak tutur khususnya kesopanan pada naskah drama agar siswa mampu mengetahui prinsip-prinsip kesopanan yang pantas untuk dipelajari oleh peserta didik dan dijadikan bahan ajar oleh guru. Membicarakan bahan ajar selalu berkaitan dengan materi ajar karena keduanya saling terkait.

Bahan ajar berupa seperangkat materi pembelajaran (teaching materials), dengan menampilkan kompetensi yang akan dikuasai siswa dalam kegiatan pembelajaran secara utuh dan teknik penyusunannya harus sistematis (Dikmenjur Depdiknas, 2006). Dengan demikian, dalam bahan ajar perlu pengembanganpengembangan materi pembelajaran.

Berdasarkan uraian di atas, peneliti mengambil fokus mengenai tindak kesantunan pada naskah drama dengan kajian pragmatik dikarenakan tindak kesantunan berperan penting dalam berinteraksi maupun pembelajaran. Selain itu, naskah Retno Manggali mencerminkan sosok seorang anak yang begitu menyayangi ibunya, beberapa penjaga kuburan yang benar-benar menjalankan tugasnya dengan baik sehingga peneliti mengangkat naskah tersebut untuk diteliti dan direlevansikan terhadap bahan ajar mata pelajaran Bahasa Indonesia di sekolah menengah atas, karena peneliti menganggap pantas untuk dijadikan bahan ajar karena cerita tersebut memiliki beberapa watak tokoh yang pantas untuk diteladani dan ditiru sehingga dirumuskan judul "Kesantunan Berbahasa dalam Naskah Drama Retno Manggali Karya Hanindawan dan Relevansinya sebagai Bahan Ajar Bahasa Indonesia di SMA".

\section{METODE}

Jenis penelitian ini adalah penelitian kualitatif dengan menggunakan pendekatan pragmatik yang bertujuan untuk mendeskripsikan kesantunan berbahasa dalam naskah drama Retno Manggali karya Hanindawan. Data dari penelitian ini 
adalah kesantunan berbahasa antartokoh dalam naskah drama Retno Manggali karya Hanindawan. Sumber data penelitian ini adalah naskah drama Retno Manggali karya Hanindawan. Instrumen penelitian ini adalah peneliti sendiri. Peneliti mengamati, membaca, memahami, mengidentifikasi, menginventarisasi dan mengklasifikasi kesantunan berbahasa dalam naskah drama Retno Manggali karya Hanindawan, kemudian menganalisis data tersebut. Teknik pengumpulan data yang digunakan dalam penelitian ini adalah teknik catat. Teknik analisis data dalam penelitian ini menggunakan metode agih. Sedangkan teknik dasar yang digunakan adalan teknik BUL (Bagi Unsur Langsung). Teknik lanjutan yang digunakan adalah teknik ganti (Sudaryanto, 2015: 18). Peneliti memeriksa keabsahan data dengan menggunakan teknik triangulasi.

\section{HASIL DAN PEMBAHASAN}

\section{Kesantunan Berbahasa dalam Naskah Drama Retno Manggali Karya Hanindawan}

\section{Maksim Kebijaksaan}

Maksim yang menggariskan pada prinsip untuk selalu mengurangi keuntungan dirinya sendiri dan memaksimalkan keuntungan pihak lain dalam kegiatan bertutur.

(3) Calon Arang: "Hidup dan mati itu bukan di tangan orang, dan setiap orang punya jalan kematian."
Percakapan data ke (3) tuturan menunjukkan ujaran maksim kebijaksanaan pada ujaran Calon Arang "Hidup dan mati itu bukan di tangan orang, dan setiap orang punya jalan kematian." Calon Arang tidak mau melihat Manggali terus menerus merasa bersalah akan kematiannya. Dapat dikatakan maksim kebijaksanaan karena ia meminimalkan kerugian bagi orang lain (Manggali) dan maksimalkan keuntungan bagi orang lain (Manggali).

(4) Calon Arang: "Kita tidak mampu membaca tangan Tuhan anakku. Petik saja yang bermakna agar langhkahmu penuh makna."

Data (4) di atas termasuk maksim kebijaksanaan, yaitu seorang ibu (Calon Arang) yang mengingatkan anaknya bahwa kita tidak bisa membaca takdir Tuhan, ambil saja hikmah dari setiap kejadian yang ada, dan meminta anaknya untuk tidak terus menerus menyesali apa yang sudah terjadi. Dapat dikatakan maksim kebijaksanaan karena tuturan tersebut meminimalkan kerugian bagi orang lain (anaknya) dan memaksimalkan keuntungan bagi orang lain (anaknya).

\section{Maksim Penerimaan atau Pujian}

Maksim yang memaksimalkan pujian kepada orang lain dan meminimalkan cacian kepada diri sendiri. Seperti data di bawah ini

(7) Yu Rebi: "Den ayu Retno Manggali. Istri nya ndoro bagus 
Bahula, putra darah Brama, siswa Eyang Barada dari Lemah Tulis. Den ayu Retno itu wajahnya bening seperti cahaya bulan, tuturnya lembut seperti angin pagi, harum kulitnya seharum bunga tanjung."

Tuturan data (7) tersebut termasuk maksim pujian atau penerimaan. Dikatakan maksim penerimaan atau pujian karena penutur menuturkan tuturan dengan tidak mencaci orang lain. Yu Rebi mengungkapkan bahwa ia memuji atau memberikan penghargaan kepada Retno Manggali. Maksim pujian tersebut terbukti pada tuturan, "Den Ayu Retno itu wajahnya bening seperti cahaya bulan, tuturnya lembut seperti angin pagi, harum kulitnya seharum bunga tanjung."

\section{Maksim Kedermawanan atau Kemurahan Hati}

Maksim kedermawanan merupakan maksim yang meminimalkan keuntungan bagi dirinya dan memaksimalkan keuntungan bagi pihak lain.

(9)Manggali: (memberikan bungkusan) "Ini Yu masih sebungkus Marwi: "Horok... hla kok malah dapat bagian.... (MENCIUM BUNGKUSAN) ini apa to den? (MENCIUM LAGI) Ambune kok enak... saya bawa pulang saja ya den. Buat genduk..."

Percakapan data (9) mengandung maksim kedermawanan karena meminimalkan keuntungan bagi dirinya dan memaksimalkan keuntungan bagi pihak lain. Dapat dibuktikan pada ucapan Manggali kepada Marwi, "(memberikan bungkusan) ini yu masih sebungkus." Dikatakan maksim kedermawanan karena Manggali bermurah hati untuk berbagi makanan kepada Kawir yang datang menemuinya. Sama halnya dengan maksimalkan kerugian bagi diri sendiri dan meminimalkan keuntungan bagi diri sendiri.

(10) Marwi: "Ya den, sampeyan (kamu) pulang saja, den ayu sepuh biar di sini saya temani. Nanti kalo kepengenkepengen bakmi apa kopi, biar nyuruh saya".

Tuturan data (10) mengandung maksim kedermawanan yaitu sikap Marwi yang memaksimalkan kerugian bagi diri sendiri dan meminimalkan keuntungan bagi diri sendiri. Marwi yang dermawan bersedia untuk menemani Calon Arang (Den Ayu Sepuh), bermurah hati untuk melayaninya dan menyuruh Manggali pulang.

Maksim Kesederhanaan atau Kerendahan Hati

Maksim kesederhanaan merupakan maksim yang bersikap rendah hati dengan cara mengurangi pujian terhadap dirinya sendiri.

(11)Yu Rebi: "Iyaa... iyaaa... mengerti. Saya ini Yu Rebi, juru masak dari Daha kerja saya itu saban hari hanya memasak." 
Tuturan data (11) tersebut menunjukkan adanya maksim kerendahan hati, yaitu pada ucapan atau tuturan Yu Rebi, "kerja saya itu saban hari hanya memasak." Ia sangat sederhana, rendah hati yaitu merendahkan diri dan pekerjaanya, tanpa malu mengakui dirinya yang hanya tukang masak. Dapat dikatakan maksim kerendahan hati karena tuturan di atas bersikap rendah hati dengan cara mengurangi pujian terhadap dirinya sendiri.

(13) Manggali: "Tapi tidak seorang pun yang mau mengerti kepedihanku. Tidak. Aku sendiri tidak akan menghiba kepada siapa-siapa. Rasa cintaku pada ibu lebih berharga daripada sekadar mengeluh."

Pernyataan data (13) di atas termasuk maksim kesederhaan yang ditunjukkan pada tuturan "Rasa cintaku pada ibu lebih berharga daripada sekadar mengeluh." Yaitu seorang anak yang lebih mengutamakan ibunya dibanding dengan keperluan dia sendiri (mengeluh), yang membuat ia kuat karena mencintai ibunya.

\section{Maksim Kecocokan}

Maksim kecocokan merupakan maksim yang mempunyai kococokan atau kesepakatan di dalam kegiatan bertutur dan memaksimalkan kesetujuan dengan orang lain.

(14) Calon Arang: "Kamu seorang anak yang tidak pernah melupakan ibunya."

Manggali: "Ini aku bawakan makanan kesukaan ibu."
Dialog pada data (14) tersebut menunjukkan adanya maksim kecocokan, yaitu penutur memaksimalkan rasa kecocokan di antara penutur dan mitra tutur. Kecocokan tersebut terbukti pada saat Calon Arang mengetahui anaknya tiba dan membawakan makanan untukya dan seketika Calon Arang menyapa anaknya dengan tuturan, "Кати seorang anak yang tidak pernah melupakan ibunya," dan dijawab oleh Manggali "Ini aku bawakan makanan untuk ibu." Percakapan tersebut terjadi kecocokan antara keduanya.

(16) Calon Arang: "Ada bakmi?" Manggali: "Ini, bakmi dari mbok Citro langganan ibu."

Tuturan pada data mengandung maksim kecocokan, karena berhasil membina kecocokan bertutur antara keduanya dengan santun dan memaksimalkan kesetujuan atau keuntungan bagi orang lain. Calon Arang yang bertanya kepada Manggali, “Ada bakmi?" lalu Manggali menjawab, "Ini, bakmi dari mbok Citro langganan ibu."

\section{Maksim Kesimpatian}

Maksim kesimpatian merupakan maksim yang memaksimalkan kesimpatian kepada orang lain dan meminimalkan antipasti kepada orang lain.

(19) Calon Arang: "(kepada Manggali) sebaiknya kamu pulang. Di kuburan hawanya dingin, lama-lama merusak tubuhmu sendiri." 
Pernyataan data (19) di atas, termasuk maksim kesimpatian, dikatakan maksim kesimpatian karena memaksimalkan kesimpatian kepada orang lain dan meminimalkan antipati kepada orang lain. Dan tuturan di atas merupakan tuturan seorang ibu yang merasa simpati, merasa kasian, tak tega melihat anaknya yang tidak mau pulang karena belum bisa mengikhlaskan kepergian ibunya-si Calon Arang.

(20) Yu Rebi: "Bukan hanya den Bagus Bahula yang merasa kehilangan, sejak den ayu pergi dari rumah. Saya pun merasa nglangut dan mengkhawatirkan keselamatan den ayu. Pulang ya den..."

Tuturan data (20) mengandung maksim kesimpatian yang dituturkan oleh Yu Rebi juru masak kepada majikannya Retno Manggali, ia merasa simpati, khawatir, dan nglangut (merasa kasian atau sedih) ia sangat khawatir dengan keselamatan majikannya yang meninggalkan rumah dan tidak mau pulang. Berhasil dikatakan maksim kesimpatian karena tuturan di atas meminimalkan antipasti kepada orang lain dan memaksimalkan simpati kepada orang lain.

Relevansi Kesantunan Berbahasa dalam Naskah Drama Retno Manggali Karya Hanindawan sebagai Bahan Ajar Bahasa Indonesia di SMA

Kesantunan berbahasa dalam naskah drama ini dapat direlevansikan dengan salah satu KD (Kompetensi
Dasar) di SMA khususnya kelas XI, yaitu KD 3.19 menganalisis isi dan kebahasaan drama yang dibaca atau ditonton. Berdasarkan hasil analisis tindak kesantunan berbahasa yang telah diteliti, peneliti mengaitkan dengan isi dan kebahasaan berdasarkan KD tersebut.

Bahan ajar atau materi isi dan kebahasaan drama dari kompetensi dasar tersebut, data dari hasil penelitian ini dapat membantu peserta didik dalam menganalisis tindak kesantunan berbahasa khususnya kesantunan menurut Leech yang terdiri dari beberapa maksim pada drama yang dibaca atau ditonton. Selain itu, keterkaitannya dapat dimunculkan dalam pembelajaran Bahasa Indonesia dengan materi ajar memahami serta mengetahui isi dan kebahasaan pada drama yang dibaca atau ditonton. Suherli (2017: 376) menyatakan kebahasaan dalam drama memiliki beberapa ciri-ciri atau aspek seperti berikut:

(1) Menggunakan banyak kata yang menyatakan urutan waktu (konjungsi kronologis). Contoh: sebelum, sekarang, setelah itu, mula-mula, kemudian.

(2) Menggunakan banyak kata kerja yang menggambarkan suatu peristiwa yang terjadi. Seperti menyuruh, menobatkan, menyingkirkan, menghadap, beristirahat.

(3) Menggunakan banyak kata kerja yang menyatakan sesuatu yang dipikirkan atau dirasakan oleh 
tokoh. Contoh: merasakan,

Kontribusi Kajian Pragmatik menginginkan, mengharapkan, mendambakan, mengalami.

(4) Menggunakan kata-kata sifat (descriptive language) untuk menggambarkan tokoh, tempat, atau suasana. Kata-kata yang dimaksud, misalnya, rapi, bersih, baik, gagah, kuat.

Secara garis besar relevansi penelitian ini dengan bahan ajar Bahasa Indonesia yang dapat dimunculkan dalam bahan ajar menganalisis isi dan kebahasaan drama yaitu memahami isi dalam drama, memahami tuturantuturan kesantunan yang ada pada drama dan mengetahui aspek kebahasaan yang digunakan pada drama yang dibaca atau ditonton. Contoh:

Calon Arang: "Kita tidak mampu membaca tangan Tuhan anakku."

Tuturan di atas diambil dari penggalan naskah Retno Manggali yang menceritakan seorang anak yang begitu menyayangi ibunya. Pada tuturan tersebut yang bercetak tebal termasuk aspek kebahasaan kata ganti, dan dapat dianalisis pula masuk dalam kategori maksim kebijaksanaan karena tuturan tersebut tuturan seorang ibu yang memimalkan kerugian bagi orang lain dan memaksimalkan kerugian bagi orang lain.

Khususnya Tindak Kesantunan dalam Menjelaskan Unsur Intrinsik Sastra

Kontribusi tindak kesantunan berbahasa dalam naskah drama Retno Manggali karya Hanindawan dalam menjelaskan unsur intrinsik sastra (amanat). Amanat itu sendiri terkadang disampaikan dalam bentuk saran, seruan, anjuran, maupun larangan. Tujuan dari amanat yaitu agar menikmat karya sasta (pembaca, pendengar, dan juga penonton) bisa mengambil hikmah dan pelajaran dari karya yang dibaca atau didengar. seperti di bawah ini.

\section{Maksim Kecocokan}

Maksim kecocokan pada penggalan tuturan naskah Retno Manggali adanya kontribusi antara tindak kesantunan dalam menjelaskan amanat. Amanat yang terkandung yaitu agar kita berbakti kepada orang tua. Dibuktikan oleh tuturan di bawah ini.

(Lalu muncul Manggali
membawakan seperangkat
makanan untuk ibunya,)
Calon Arang: Kamu seorang
anak yang tidak pernah
melupakan ibunya.
Manggali: Ini aku bawakan
makanan kesukaanibu. (Data 13)
Maksim selanjutnya yaitu
sim kesederhanaan ini dapat
mbil amanat agar kita tetap
cintai ibu kita sampai kapan pun, di
tikan oleh data (12) yaitu tuturan

Manggali, "Tapi tidak seorang pun 
yang mau mengerti kepedihanku. Tidak. Aku sendiri tidak akan menghiba kepada siapa-siapa. Rasa cinta ku kepada ibu lebih berharga dari pada sekedar mengeluh".

Penggalan naskah di atas menunjukkan adanya kontribusi tindak kesantunan maksim kecocokan dan maksim kesederhaan dalam menjelaskan amanat kepada pembaca atau penonton dengan mencerminkan sikap Manggali yang berbakti kepada orang tua dan selalu mengutamakan ibunya dibanding kebutuhan dirinya sendiri (mengeluh). Amanat dari naskah Retno manggali yang pertama yaitu berbaktilah kepada orang tua dan cintailah ibu kita sampai kapan pun, karena ibu adalah sosok wanita yang paling tangguh selalu berkorban untuk anak-anaknya.

\section{Maksim Kedermawanan (Kemurahan Hati)}

Maksim kedermawanan pada tuturan naskah drama Retno Manggali memberikan kontribusi antara tindak kesantuan dalam menjelaskan amanat. Amanat yang terkandung yaitu agar kita selalu bermurah hati, berbagi kepada sesama dan bersikap dermawan kepada siapa pun. Dibuktikan oleh tuturan dialog di bawah ini.

Manggali: "(memberikan bungkusan) ini yu masih sebungkus." Marwi: "Horok... hla kok malah dapat bagian.. (mencium bungkusan) ini apa to den? (mencium lagi) Ambune kok enak... saya bawa pulang saja ya den. Buat genduk..." (Data 9)
Marwi: "Ya den, sampeyan pulang saja, den ayu sepuh biar di sini saya temani. Nanti kalo kepengen-kepengen bakmi apa kopi, biar nyuruh saya." (Data 10)

Tuturan data (9) dan (10) di atas menunjukkan adanya kontribusi tindak kesantunan maksim kedermawanan atau kemurahan hati dalam menjelaskan amanat kepada pembaca maupun penonton drama dengan mencerminkan sikap Manggali yang berbagi makanan kepada marwi (penjaga kuburan). Begitupun Marwi kepada Manggali yang ingin membantu melayani Calon Arang (ibu Manggali) jika menginginkan sesuatu biar menyuruh saya saja dan memberi saran Manggali untuk pulang. Amanat yang terkandung dan dapat diteladani yaitu kita harus mampu bersikap murah hati, berbagi kepada sesama dan bersikap dermawan kepada siapa pun.

Penelitian ini sejalan dengan Liana (2016) yang meneliti kesantunan berbahasa dalam naskah drama Umang-Umang karya Arifin C. Noer dan implikasinya terhadap pembelajaran Bahasa dan Sastra Indonesia di SMP juga sejalan dengan penelitian yang dilakukan oleh Beden \& Zahid (2015) berjudul "Paparan Kesopanan Berbahasa dalam Teks Komsas Melunas Rindu: Aplikasi Model Leech (1983) dan Grice (1975)"

\section{SIMPULAN}

Tindak kesantunan berbahasa ditemukan sejumlah 20 data, dengan rincian maksim kebijaksanaan 2 data, 
maksim pujian 2 data, maksim kedermawanan 2 data, maksim kesederhanaan 3 data, maksim kecocokan 4 data, dan maksim kesimpatian terdiri dari 3 data. Kedua, penelitian ini direlevansikan sebagai bahan ajar Bahasa Indonesia di SMA. Keterkaitan bahan ajar digunakan untuk mendukung pembelajaran Bahasa Indonesia mengenai drama pada KD 3.19 "Menganalisis isi dan kebahasaan drama yang dibaca atau ditonton" pada peserta didik di SMA. Ketiga, yaitu penelitian ini dapat dikontribusikan dengan unsur intrinsik khususnya pada bagian amanat.

\section{REFERENSI}

Beden, S., \& Zahid, I. (2015). Paparan Kesopanan Berbahasa dalam Teks Komsas Melunas Rindu: Aplikasi Model Leech (1983) dan Grice (1975). Issues in Language Studies, 4 (2), 41-62.

Claudia, V.S., Rakhmawati, A., \& Waluyo, B. (2019). Prinsip Kesantunan Berdasarkan Maksim Leech dalam Kumpulan Naskah Drama Geng Toilet Karya Sosiawan Leak dan Relevansinya Sebagai Bahan Ajar Teks Drama di Sekolah Menengah Atas. BASASTRA, 6 (2), 197-208.

Liana, N. (2016). Kesantunan Berbahasa dalam Naskah Drama Umang-Umang Karya Arifin $C$. Noer dan Implikasinya Terhadap Pembelajaran Bahasa dan Sastra Indonesia di SMP. Skripsi Tidak Dipublikasikan. UIN Syarif Hidayatullah Jakarta.
Sudaryanto. (2015). Metode dan aneka Teknik Analisis Bahasa. Yogyakarta: Sananata Dharma University Press.

Sufanti, M., dkk. (2017). Silabus dan Rencana Pelaksanaan Pembelajaran Bahasa Indonesia: Teori dan Praktik. Surakarta: Muhammadiyah University Press.

Suherli, dkk. (2017). Bahasa Indonesia: Buku Guru/Kementerian Pendidikan dan Kebudayaan. Jakarta: Pusat Kurikulum dan Perbukuan, Balitbang, Kemendikbud. 